\title{
Familial occurrence of a syndrome with branchial dysplasia, mental deficiency, club feet, and inguinal herniae
}

\author{
J C LAMBERT*, N AYRAUD*, J MARTIN†, R MARIANI+, M FERRARI*, \\ AND M DONZEAU* \\ From * Laboratoire d'Histologie-Embryologie-Cytogénétique, Faculté de Médecine, †Service de \\ Pédiatrie, Hôpital Lenval, and $\ddagger$ Service de Pédiatrie, Hôpital de Cimiez, Nice, France.
}

SUMMARY A distinct probably autosomal recessive disorder was ascertained in a boy and his sister. The common features were signs of abnormal development of the first and second branchial arches, mental deficiency, club feet, and inguinal herniae. In addition the boy had hypospadias and the girl a ventricular septal defect.

Two sibs with multiple congenital anomalies are reported. The association of these anomalies and their suggested mode of inheritance do not seem to correspond to any well known syndrome.

\section{Case reports}

CASE 1 (FIG 1)

This was the first child of a 22-year-old mother and a 28-year-old father. He was born after a normal term pregnancy during which the mother had not been exposed to any drugs, radiation, or infectious diseases. Delivery was normal and the child's weight

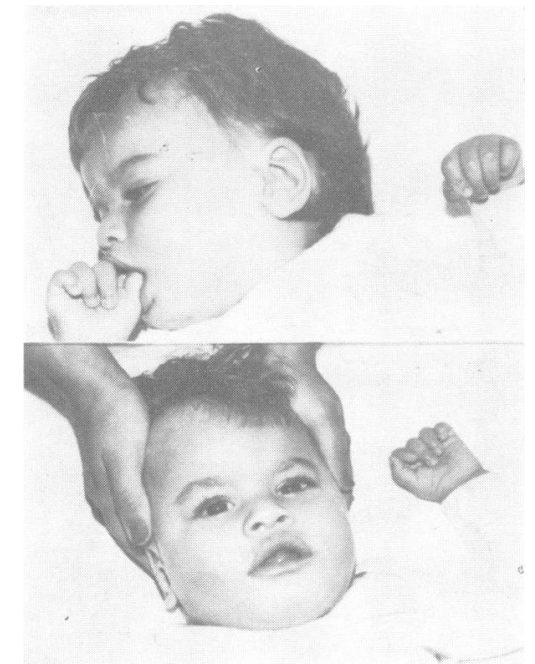

FIG 1 Case 1 at 12 months.

Received for publication 23 July 1981 was $2250 \mathrm{~g}$. Bilateral preauricular tags, an anterior hypospadias, club feet, and bilateral inguinal herniae were noted. The herniae were subsequently repaired surgically.

He was seen at the age of 12 months for an acute respiratory infection. Clinical findings at that time showed: weight $8.15 \mathrm{~kg}$, height $71.5 \mathrm{~cm}$, head circumference $45 \mathrm{~cm}$, two upper incisors, slight hypotonia, bilateral preauricular tags with normal ears, malar hypoplasia, macrostomia with lateral cleft-like extension of the corner of the mouth, hypospadias, and reducible club feet. Otological examination showed no obvious hearing loss. IQ was low (58).

Skeletal $x$-ray and routine laboratory studies of blood and urine were within normal limits. Results of blood and urine amino-acid chromatography were normal. Chromosomal analysis performed on cultured lymphocytes showed a normal male karyotype.

CASE 2 (FIG 2)

This was the sister of case 1 . She was born $10 \frac{1}{2}$ months later after an 8-month uncomplicated pregnancy and normal delivery. There was no history of drug or radiation exposure or illness during pregnancy.

Clinical findings at birth showed: weight $2300 \mathrm{~g}$, height $48 \mathrm{~cm}$, head circumference $32 \mathrm{~cm}$, right ear represented by the remains of the lobe and concha with meatal atresia and a preauricular appendage and fistula, left ear normal in size but with meatal atresia and a preauricular fistula and appendage, malar hypoplasia, macrostomia, right inguinal hernia, and club feet. 


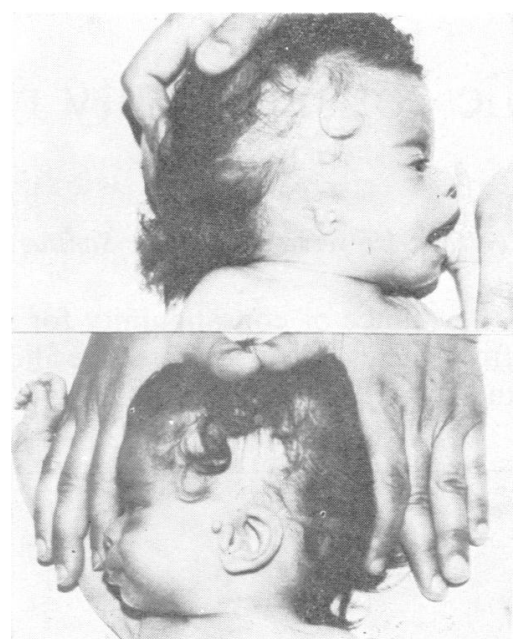

FIG 2 Case 2 at 3 months.

At 5 days, a systolic precordial murmur was heard and cardiological examination showed a ventricular septal defect.

At 17 days, jaundice appeared and its duration led to exploratory surgery of the extrahepatic bile ducts which were normal. Histologically, giant cell hepatitis was found.

The jaundice disappeared gradually but growth and mental development were retarded. At 1,3, and 6 months, respectively, weights were $2.20 \mathrm{~kg}, 2.45 \mathrm{~kg}$, and $3 \cdot 15 \mathrm{~kg}$. Heights were $48 \mathrm{~cm}, 50 \mathrm{~cm}$, and $60 \mathrm{~cm}$, and head circumferences were $34 \mathrm{~cm}, 35 \mathrm{~cm}$, and $38.5 \mathrm{~cm}$. No motor progress was noted.

$X$-ray of the spine and an intravenous pyelogram were normal. Laboratory studies were within normal limits or negative except for during the jaundice. Karyotype was normal.

The parents are first cousins. Two years before the first pregnancy the mother had had persistent stomach aches which led to a complete radiological examination of the stomach, bowels, and biliary tract, all of which were within normal limits. Nine years before the father had undergone 6 months' treatment for tuberculous pleurisy. There was no family history of congenital malformations.

\section{Discussion}

In both cases there were facial abnormalities, mental deficiency, club feet, and inguinal herniae; in addition the male had hypospadias and the girl a ventricular septal defect.

The malformations of the head could be associated with one of the first or second branchial arch syndromes. Of these, hemifacial microsomia with its unilateral signs can easily be excluded. With regard to the Treacher-Collins syndrome, in spite of its wide variability of expression, commons signs such as antimongoloid slant of the palpebral fissures, mandibular hypoplasia, and lower lid colobomata were not present in our cases. On the other hand, preauricular tags are sometimes found in this syndrome. In the Goldenhar syndrome, the distinguishing features include dermoids, lipodermoids, or lipomas of the eyes, colobomata of the upper lids, and vertebral abnormalities, none of which were found in our cases.

The association of mental deficiency and the other malformations with facial abnormalities must be considered. In the Treacher-Collins syndrome mental deficiency has been reported in only $5 \%$ of the cases. ${ }^{1}$ Limb deformities may be associated with mandibulofacial dysostosis (absence of radius, radioulnar synstosis, and hypoplasia of the thumb in Nager's acrofacial dystosis syndrome ${ }^{2}$ or split feet ${ }^{3}$ ), but do not include club feet. In the Goldenhar syndrome mental deficiency and club feet are more commonly found (in approximately $20 \%$ of the cases) and ventricular septal defect has been found in several cases. However, inguinal herniae are not part of any first or second branchial arch syndrome, even as an occasional finding.

Familial occurrence in two children of both sexes of unaffected consanguineous parents, the lack of exposure to teratogenic factors, and the normal karyotypes indicate an autosomal recessive mode of inheritance. Treacher-Collins syndrome is a Mendelian dominant disorder and the Goldenhar syndrome is usually sporadic; only two cases of autosomal recessive inheritance have been reported. 45

The present observations seem to correspond to a syndrome of branchial dysplasia, mental deficiency, club feet, and inguinal herniae, similar to Goldenhar syndrome, and probably autosomal recessive.

\section{References}

1 Smith DW. Recognizable patterns of human malformation. 2nd ed. Philadelphia: Saunders, 1976:134.

2 Bowen P, Harley F. Mandibulofacial dysostosis with limb malformations (Nager's acrofacial dysostosis). Birth Defects $1974 ; \mathbf{X}(5): 109-15$.

- Patterson TJS, Stevenson AC. Craniofacial dysostosis and malformation of the feet. $J$ Med Genet 1964;1:112-4.

4 Saraux H, Grignon JL, Dhermy P. A propos d'une observation familiale de syndrome de FranseschettiGoldenhar. Bull Soc Ophtalmol Fr 1963;63:705-7.

5 Krause U. The syndrome of Goldenhar affecting two siblings. Acta Ophthalmol 1970;48:494-9.

Requests for reprints to Dr J Lambert, Laboratoire d'Histologie-Embryologie-Cytogénétique, Faculté de Médecine, Chemin de Vallombrose, 06034 Nice Cedex, France. 